\title{
Blockchain Technologies: A Study of the Future of Education
}

\author{
M. Jayne Fleener \\ North Carolina State University
}

This paper provides insights into the possible, plausible and desirable futures of using blockchain technologies in education. While several universities and education providers are already beginning to use blockchain technologies for complex record manipulations, accounting, and certification of credentials, a whole-systems approach provides a broader view of the issues, promises and challenges associated with using blockchain technologies in education. The study uses social inquiry and causal layered analysis (CLA) to explore impacts across social, economic, environmental, policy, and values dimensions. Findings suggest the needs for new driving metaphors and myths about the purpose and value of education and its place in society as a public good, challenging traditional narratives of the importance and value of formal education and degrees. The implications of this study include a consideration of wider social factors that become important for implementing transformative change in education, presenting challenges to traditional K-12 and higher education curriculum, outcomes, and infrastructure.

Keywords: assessment, blockchain, lifelong learning, informal learning, systems theory, higher education

\section{INTRODUCTION}

Distributed ledger technologies (DLT) have evolved to support many applications in the fields of healthcare (Egelhardt, 2017), automotive industry (Dorri et al., 2017), voting, personal data storage, new forms of entrepreneurship and personnel data processing, to name a few (Srivastava et al., 2019; Whitaker, 2019). Among the first and most recognized uses of DLT was for supporting cryptocurrencies, including Bitcoin. DLT approaches are built on what are referred to as Blockchains.

Blockchain extends traditional database technologies by creating mechanisms for a ledger system that is distributed across users, creating multiple interlocking copies making centralized ownership and maintenance of the information obsolete (Nakamoto, 2009). Blockchain data networks are designed to (1) have no central authority, (2) be accessible to all participants across the network, (3) have built-in security to prevent non-authorized modification of data, and (4) support and keep track of verified data transactions.

The history of distributed ledger technologies extends well before the 2009 launch of the Bitcoin blockchain by Satoshi Nakamoto (Wallace, 2011) to the beginning of personal computers and early concerns about how to address challenges of data permanence and security (Whitaker, 2019). The same questions that troubled Haber and Stornetta (Haber \& Stornetta, 1991a, 1991b) as they developed distributed ledge technologies are relevant today when we consider compiling, sharing, and securing educational data and will be explored in this paper. Below are specific areas of promise that are especially relevant to educational applications of blockchain technologies. 


\section{Applications of Blockchain}

Blockchain applications take advantage of the characteristics of secure, digital registry technologies and have been used to support a variety of data management needs (see, for example, Evans, 2019; Gurkaynak et al., 2018; McKinney et al., 2018; Whitaker, 2019). Digital records that can be shared across users and kept for historical and permanent archival documentation and retrieval are important features of DLT that have numerous public and private sector possibilities. The four advantages of blockchain technology are: reliability because of decentralization of data, trust, also building from no centralized control or ability to erase past transactions, security, creating a semi-permanent footprint of all transactions, and efficiency of access and labor to reconcile transactions (Chen et al., 2018).

Swan (2015) described the use of blockchain technologies as evolving through three different stages. The first stage reverts back to early uses with the development of cyrptocurrencies and the use of blockchain for accounting documentation. The second stage of blockchain use includes more complicated information transfer, especially in the areas of smart contracts, loans, and stocks and bonds. The third stage, which is only now beginning to emerge, is in the areas of government, health, science, literacy, culture, and arts applications (Chen et al., 2018). Education applications, especially as related to workforce development, falls within this emerging third (or maybe even forth) stage of application.

As blockchain applications are being explored, concerns are being raised about attempts to regulate and fund blockchain use by governmental entities. Krzyzanowski-Guerra and Boys (2021) describe efforts and obstacles to develop and use DLT to address food safety and support small-scale farming operations. They cite several studies (e.g., Kamilaris et al., 2019; Yadav et al., 2020; Zhao et al., 2019) that also convey concerns about regulatory uncertainty and oversite. These concerns and obstacles will be relevant as we explore possible uses in education.

Futures studies have occurred to explore applications of blockchain technologies. Höhne and Tiberius (2020), for example, used the Delphi Method to explore how blockchain might be used in the electricity market and Alarcon (2018) describes possible future applications of blockchain to accounting. The exploration of blockchain solutions to data sharing needs are occurring across many sectors of society.

Education is part of the blockchain conversation. The question of how blockchain can be used in education has been asked by a variety of entrepreneurs, educators, and policy makers. A short summary of the status of the field will be presented below before reporting on the current study of the possible, plausible, and desirable futures approaches to using blockchain technologies in education.

\section{Current Uses of Blockchain in Education}

Blockchain technology is beginning to be explored by some universities for degree management and learning outcomes accountability (Sharples \& Domingue, 2016; Skiba, 2017). Building on the capacity to keep track of skills and non-traditional learning experiences, the University of Nicosia is leading the conversation by exploring how to document informal learning from recognized providers such as MOOC courses (Sharples \& Dominique, 2016). Sony Global Education is also standing out for efforts to develop blockchain strategies to offer support for storage and management of degree information (Hoy, 2017) and MIT is exploring digital badging parameters for use in blockchain education applications (Skiba, 2017). It has been suggested that blockchain technologies can help reduce degree fraud (Chen et al., 2018) by managing and maintaining student degree information that cannot be tampered with. Applications of blockchain for storing information about other experiences, skills, knowledge, and dispositions are just beginning to be explored (Sharples \& Domingue, 2016).

Blockchain technology has been a focus in China for education as well as financial applications. China's "Thirteenth Five-Year Information Plan" was released in October 2016 and includes using blockchain technologies for educational data compilation and student information management systems to keep track of and share student academic accomplishments across learning and work contexts and experiences (Zhou \& Wang, 2020). Emphasis is being placed in China to develop blockchain knowledge and expertise with a variety of schools and organizations teaching the next generation of blockchain experts who will develop new approaches to digitization and networking (Li, 2020). 
Building on these efforts to apply blockchain technologies in education in a piecemeal fashion, this study explores the possible, plausible, and preferred uses of blockchain technologies in education grounded in a social systems perspective. Using social inquiry methodology, this study stays focused on the "conceptual need to link social behavior to wider social systems" (Greene, 2008, p.7). The Millennium Projects' recent report (Glenn, 2020) provides the basis for a systems-wide exploration of the future of educational uses of blockchain technologies, especially in relation to workforce preparation and development. Consistent with social inquiry, a deeper perspective is achieved using the futuring approach of Causal Layered Analysis (CLA) (Inayatullah, 1999, 2008) that explores underlying social and education myths and metaphors within STEEPA (Social, Technological, Environmental, Economic, Political and Arts/Values) dynamics. It will be argued that the myths and metaphors upon which our current educational system relies are no longer valid in highly technological and rapidly changing social environments and in the context of the need for ubiquitous, continuous, and pervasive lifelong learning. The future of learning, workforce development and formal education will be explored using a blockchain approach where individuals carry, throughout their lives, their individual performance and lifelong learning credentials. A blockchain approach will disrupt the one-size-fits-all curriculum and approach to education in support of many alternative learning formats including nonformal and informal as well as formal educative experiences. The implications of this research are far-reaching, presenting challenges to traditional K-12 and higher education curriculum, outcomes, and infrastructure.

\section{RESEARCH APPROACH}

This study uses a social inquiry framework within a futures orientation to explore the future of blockchain possibilities in education. A combined futures and social inquiry approach allows questions about future possible, probable and desirable opportunities to be examined from a social systems perspective. A social systems understanding of complex problems for which predictability and control are not possible considers that dynamic, emergent, and comprehensive influences can impact and guide change. The results of a social inquiry study from a futures perspective introduces opportunities for in-depth and sustained discussions for emergent possibilities for educational futures.

\section{Social Inquiry}

Social inquiry was first used in anthropology to study the "conceptual need to link social behavior to wider social systems to meaningfully make interpretive sense of localized phenomena" (Greene, 2008, p.7). Social inquiry focuses beyond individuals, individual contexts, and human decision making and control to understand complex relationships at individual, social, institutional, and environmental levels. It is therefore a useful methodology to understand complex social phenomena when predictability and control are not possible.

Social inquiry utilizes a variety of qualitative, quantitative, and mixed methods research approaches to explore complex social dynamics that include human, environmental, governmental, and natural dimensions (Fox \& Alldred, 2015). Social inquiry is especially valuable for complex studies involving challenges across institutional and societal as well as individual and cultural perspectives (Greene, 2008) and assumes complex relationships undergird our social world, placing social inquiry within a postmodern ontological frame. This ontological perspective considers human experiences and relationships on an equal footing with social and environmental dynamics (Fox \& Alldred, 2015) supporting the need to consider our place in the world from social, technological, economic, environmental, political, and artistic/values (STEEPA) dimensions. How we make sense of our social world (epistemological perspective) is within the context of these STEEPA relations and impacts our values, beliefs and understandings of processes and interactions and our actions that shape potential futures. Social inquiry methodology "foregrounds an appreciation of just what it means to exist as a material individual with biological needs yet inhabiting a world of natural and artificial objects, well-honed micro-powers of governmentality, but no less compelling effects of international economic structures" (Coole \& Frost, 2010, p. 27). Social inquiry promotes a 
complex adaptive social systems perspective of society (Dixon, 1984) and offers strategies to explore how we engage with and become a part of the ensembles of society.

\section{Futuring Strategies}

As futurists develop and expand their skills and techniques to facilitate futuring activities (Hines et al., 2017), there has been an evolution from epistemological focus on prediction, control, and optimization (Miller, 2015; Poli, 2018) to supporting emergent, transformative possibilities through futures engagements (Miller, 2018). Sohail Inayatullah $(1998,2008)$ describes the Causal Layered Analysis (CLA) approach to futures inquiry that supports transformational change at individual and social levels. This social inquiry research will use the CLA futures approach as a framework for exploring societal relationships and connections across STEEPA categories related to the possible and preferred futures of education with regards to the adoption of blockchain technologies.

Futurists explore possible, probable, and preferred futures from a variety of perspectives. James Dator (2011) has explored individual and group approaches to the future and identified four major archetypes of perspectives about the future: Growth, Collapse, Constraint, and Transformation. Growth perspectives are grounded in growing existing structures and use language of progress, prosperity, profit, strategy, and purpose. Collapse perspectives of the future depict perspectives of failure of infrastructure and understandings, implying that unfettered growth or progress will eventually lead to collapse. Constraint approaches to the future check unconstrained growth by incorporating policies, rules, regulations, and practices that provide for more disciplined growth or interaction. In all three of these approaches to the future, there typically is not a critical examination of existing values or underlying beliefs nor challenges to ultimate goals for the future. There is also an assumption that key operations and relationships will continue in the future as they have in the past.

Transformative approaches to the future, the fourth futures perspective, explore and challenge underlying epistemological, ontological, cultural, and ethical assumptions. Transformational futures fundamentally change relationships and how we perceive them (including how we rethink the past as well as reconstruct the future), creating new dynamics and understandings at the core of who we are and society. This study will engage a social inquiry process using the CLA futuring approach to expose underlying social expectations to advance a transformational, preferred futures perspective as we consider the future of education and the use of blockchain technologies.

\section{RESEARCH DESIGN}

\section{Data Sources}

There are two primary data sources for this study. The first was generated through a multi-year study by the Millennium Project (nd) on views of what society will be like in 2050. The second data source comes from an American Council on Education (ACE) report on the potential uses of blockchain in education (Lemoie \& Soares, 2020). Each of these reports will be briefly summarized below.

\section{Millennium Project}

The Millennium Project's (nd) overall goal is to connect futurists and global leaders through research about the future. Initially established in 1996, the project has produced a variety of research reports and conducted lecture series and conferences associated with future trends and possibilities. The recent report on "Work/Technology 2050" (Glenn, 2020) was the culmination of over three years of data collection and analyses, resulting in 93 recommended actions for transformational change. Social factors necessitating a futures approach included the pace of technological change, globalization, technology transfer, standardization of databases and protocols, cultural stressors due to technological advances and the speed of change, global communication networks, and artificial intelligence. Other social factors driving the research were the social challenges resulting from a concentration of wealth resulting in widening income gaps and the impact of artificial intelligence (AI) and virtual reality (VR) on labor costs and the workforce. 
The research was conducted in several phases. The first phase involved futurists and thought leaders in a Delphi Study to explore alternative futures for work and technology. Over 300 futurists and industry leaders from over 45 countries participated in the development of these futures scenarios. Three futures scenarios were written as a result of this preliminary study. Workshops in 20 countries used these scenarios with over 450 futurists and industry leaders to develop long-range strategies to address the challenges described in the scenarios. The third stage of the research then analyzed and summarized these recommendations and assigned them to social systems categories: Government \& Governance (GG), Business \& Labor (BL), Science \& Technology (ST), Culture \& Arts (CA), and Education \& Learning (EL). The final phase of this research then shared the reported findings of the groups in workshops in 50 countries, integrating their findings in the current report of 93 recommendations to address technological and work futures in 2050 .

These 93 recommendations form the first data set to be used in this social inquiry analysis of the future of education in the context of blockchain technologies. The second data set was generated through a recent study by the American Council on Education (ACE) described below.

\section{American Council on Education Report}

The American Council on Education (ACE) report on "Connected Impact: Unlocking Education and Workforce Opportunity through Blockchain" (Lemoie \& Soares, 2020) was prompted by the challenges of a widening gap between workforce demands and formal education preparation. Additional challenges motivating this report included the underemployment and under-representation of women and minorities in the workplace and credentialing of skills not addressed through formal education.

The Report compiled uses of and challenges with blockchain technologies to document, verify and communicate workforce skills. Emerging themes of the report include issues of personal data agency and privacy, lifelong learning, and emerging blockchain ecosystems. Over 70 blockchain applications in education were described in the report (Schaffhause, 2020), providing a state-of-use summary of blockchain technologies in education.

\section{Analyses}

Causal Layered Analysis (CLA) was used to analyze data generated through the Millennium Project (MP) and ACE reports. Grounded in postructural theory, CLA "provides a richer account of what is being studied than the more common empiricist or predictive orientation" (Inayatullah, 1998, p. 815). CLA has four dimensions of ever-increasing depth of analysis: Litany, Systems, Worldview, and Myths (see Figure 1). The CLA approach supports "creating transformative spaces for the creation of alternative futures" (p. 815) and is appropriate for a social systems inquiry into blockchain education futures at the genesis of exploration of uses of blockchain technologies in education. CLA, as a postmodern investigative strategy, is particularly consistent with the goals of this research to promote thinking and exploration of possible and preferrable education futures, providing opportunities for rich and informed discussions to shape the futures we want in education. CLA includes creating visual and mythical alternatives to existing worldviews, being "more concerned with evoking visual images, with touching the heart instead of reading the head" (p. 820). Each of these layers of analysis is described below. 
FIGURE 1

CAUSAL LAYERED ANALYSIS (CLA) PHASES

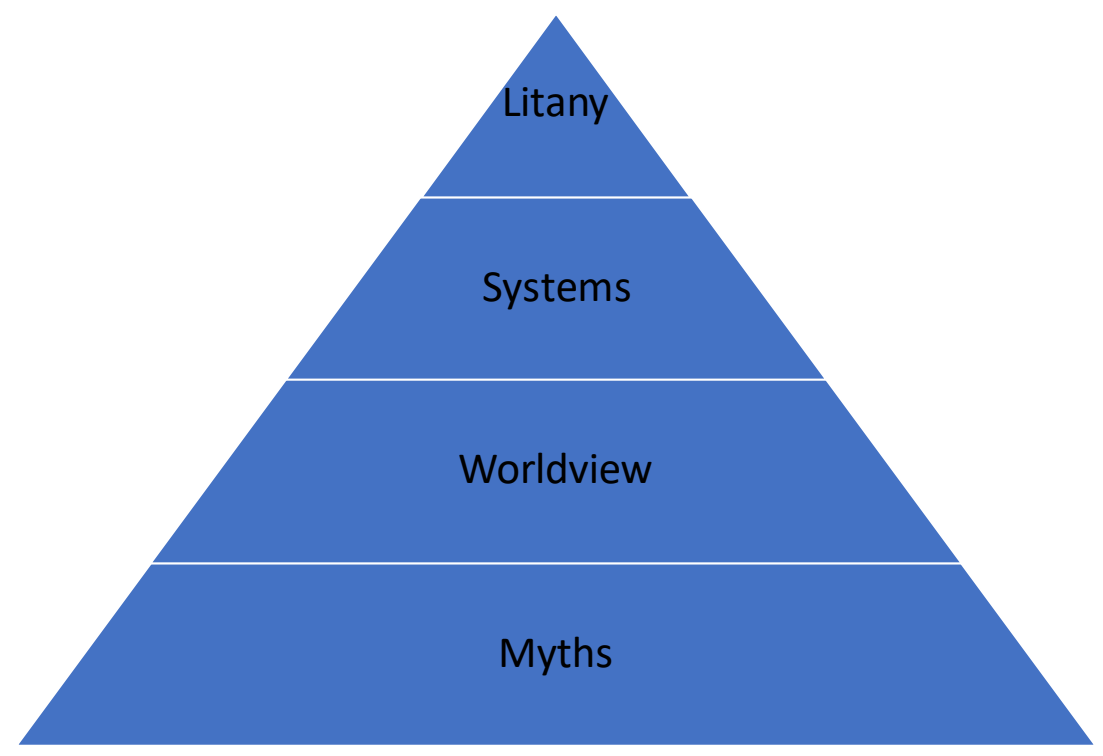

\section{Litany Analysis}

The first layer of the CLA analysis lays out the problem and provides a first level of analysis of the problems, relationships, perceived causes and solutions. It offers a "litany" or series of initial solutions or approaches to the problem.

Thematic (Braun et al., 2019) and content analysis (Duriau et al., 2007; Neuendorf \& Kumar, 2016) were used to generate the initial list of issues, concerns, problems, and solutions by examining the $93 \mathrm{MP}$ recommendations and the ACE report findings. Thematic statements were generated from the ACE report and considered along with the 93 stated recommendations from the MP report. The problems, issues, concerns and challenges of the future of education, workforce and blockchain applications in education were then categorized by key descriptors using content analysis. Several rounds of content analysis were used to generate key descriptors which represented the litany of issues associated with education futures and blockchain technologies connected to the issues represented in the source documents. A Wordmap was used to visually display the words and concepts that emerged through the content analysis.

\section{Systems Analysis}

The next layer of the CLA analysis explores the system of relations and connections. From a social systems perspective, these relations and connections are conveyed through STEEPA categories. Because the $93 \mathrm{MP}$ recommendations were already in social system categories, the social system categories used for the systems-level analysis were Government and Governance (G), Business and Labor (BL), Science and Technology (ST), Education and Learning (EL) and Culture and Arts (CA). The 93 MP recommendations from the MP report and the 52 statements generated through the litany phase of the analysis using thematic analysis of the ACE report, produced 145 statements that were categorized into one of the five social systems categories. Content analysis of the statements, also a part of the litany analysis, allowed for an examination of key themes representing specific concerns, issues, approaches and solutions across the five social systems categories.

Rather than just a list and frequency of the constructs, as described in the litany analysis through content analysis, the systems-level analysis considers which constructs are represented across different social systems categories. The number of system-level relationships for each construct is classified to give an indication of the system-wide impact of that construct. A catalogue of key constructs that impacted multiple 
system-level perspectives is important for the next layer of analysis where underlying shifts in worldviews are analyzed.

\section{Worldview Analysis}

The third level of CLA in a social inquiry analysis is to take the key constructs appearing across social systems categories to provide insights into the worldview that is represented by those constructs and understandings. The worldview analysis specifically addresses the worldview as it relates to the future of education in the context of blockchain technologies. A worldview begins to emerge as the overlapping ideas across social dimensions constitute a futures discourse (Inayatullah, 1998). The overlapping constructs tell a story about how the future can be perceived and underlying values and assumptions that are important for understanding possible futures. Thematic analysis (Braun et al., 2019) was used for the worldview layer of analysis in this study. The Worldview analysis becomes the basis for generating new myths and metaphors for the future to support transformative change perspectives as described in the fourth layer of the CLA, below.

\section{Mythical Analysis}

Extending the interpreted worldview as conveyed in the third level of the CLA analysis, the fourth layer of analysis considers emerging myths or metaphors that may be needed to support transformational change. "This level provides a gut/emotional level experience to the worldview under inquiry...more concerned with evoking visual images, with touching the heart instead of reading the head" (Inayatullah, 1998, p. 820). The emerging myths and metaphors as an extension to the worldview analysis are summarized and depicted as shifting ideas about the relationship between education, blockchain, workforce, and technology are conveyed through visual imagery.

As a postmodern approach to inquiry, systems inquiry using CLA is not intended to predict, analyze or objectively convey futures' possibilities, but is intended to create "transformative spaces for the creation of alternative futures" (Inayatullah, 1998, p. 815).

\section{Guiding Questions}

The guiding questions for this study are: (1) what are the opportunities and challenges to public education introduced by blockchain technologies? and (2) how may blockchain technologies support a different vision of the future of education?

The first question will be answered through the level 1 and level 2 CLA analyses of the 145 recommendations and social system perspectives of the MP and ACE data. The second question will be addressed by extending level 3 and level 4 CLA analyses to embed blockchain implementation strategies within emerging worldviews and myths about the future as they impact education.

\section{FINDINGS}

The findings of the study will be presented by CLA approaches. Each separate analysis will be presented below. Guiding questions will then be addressed in the discussion section of the paper.

\section{Litany}

Each of the 93 recommendations from the Millennium Project (MP) report provided an initial visionary statement about the future. For the American Council on Education (ACE) report, statements were generated based on a careful reading of the strategies, visions, initiatives and expectations for future uses of blockchain technologies and education. 52 statements were generated from the ACE report using thematic analysis (Braun et al., 2019). For example, the statement "Addressing social equity issues with regard to education and employment outcomes" was generated as a summary statement found on page 12 of the report describing implications for the use of blockchain technologies in education.

The 93 recommendations from the MP and the 52 statements from the ACE report served as the initial data sources for the litany phase of the CLA. Once the 145 statements were generated, the first round of 
analysis identified key descriptors for each of the 145 statements. Content analysis (Duriau et al., 2007; Neuendorf \& Kumar, 2016) was used to identify the initial descriptors to look for emergent themes. After the first round of analysis, 430 construct descriptors (with repetition) were identified. A second reading of all of the recommendations and statements and exploration of the 430 construct descriptors identified key underlying values, assumptions, strategies or approaches, allowing for a pairing down of the initial identifiers. For example, some of the value statements pointed to a broader perspective about a new social contract of providing new opportunities for all citizens. After this second round of analysis, the 430 construct descriptors were narrowed down to 245 non-distinct key words or concepts. A few examples appear in Table I below to provide a sense of how the initial data set was organized. (See Table 1 below). The source of the data was either the Millennium Project (MP) statements or the American Council on Education (ACE) statements generated through thematic analysis. Statements were assigned to or already identified with the social system categories. The constructs allowed for comparison across statements and formed the basis of the litany analysis.

TABLE 1

SAMPLE STATEMENTS AND CONSTRUCT CLASSIFICATIONS

\begin{tabular}{|c|c|c|c|}
\hline Source & $\begin{array}{l}\text { Social } \\
\text { Cate }\end{array}$ & Statement & Constructs \\
\hline \multirow{5}{*}{ ACE Stt } & BL1 & $\begin{array}{l}\text { Issuing and verification of academic and work records (CVs, } \\
\text { portfolios) }\end{array}$ & $\begin{array}{l}\text { verification, } \\
\text { documenting }\end{array}$ \\
\hline & CA1 & attributes of blockchain - transparency, trust, tamper resistant & $\begin{array}{l}\text { transparency, } \\
\text { trust, security }\end{array}$ \\
\hline & EL1 & evidence of learning, recommendations, and work experience & credentialing \\
\hline & GG5 & $\begin{array}{l}\text { Data ownership can be muddy, especially considering legislation } \\
\text { such as General Data Protection Regulation (GDPR) and Family } \\
\text { Education Rights and Privacy Act (FERPA }\end{array}$ & $\begin{array}{l}\text { privacy, } \\
\text { decentralize, } \\
\text { ownership }\end{array}$ \\
\hline & ST1 & management and display of aggregated records & $\begin{array}{l}\text { technology, } \\
\text { access, } \\
\text { management }\end{array}$ \\
\hline \multirow{5}{*}{ MP Stt } & BL12 & $\begin{array}{l}\text { Develop ways for companies and employees to create ethical, } \\
\text { aesthetic and social value in addition to economic and material } \\
\text { value }\end{array}$ & $\begin{array}{l}\text { self } \\
\text { actualization, } \\
\text { social contract }\end{array}$ \\
\hline & CA16 & $\begin{array}{l}\text { Repurpose libraries, old post offices, movie theaters, national } \\
\text { parks, museums as well as "maker spaces" as "creative } \\
\text { placemaking" hubs for integrating the arts and community } \\
\text { building - a nexus for creative contribution, lifelong learning, } \\
\text { cultural exchange, and Next Tech/digital connection places }\end{array}$ & $\begin{array}{l}\text { lifelong } \\
\text { learning }\end{array}$ \\
\hline & $\mathrm{E} 02$ & $\begin{array}{l}\text { Shift education/learning systems more toward mastering skills } \\
\text { than mastering a profession }\end{array}$ & $\begin{array}{l}\text { lifelong } \\
\text { learning }\end{array}$ \\
\hline & G19 & $\begin{array}{l}\text { Create a new social contract between government and the } \\
\text { governed }\end{array}$ & $\begin{array}{l}\text { self } \\
\text { actualization, } \\
\text { social contract }\end{array}$ \\
\hline & ST10 & $\begin{array}{l}\text { Create national policies and standards for the internet of things } \\
\text { (IoT) that stresses future cyber security systems }\end{array}$ & $\begin{array}{l}\text { security, } \\
\text { connect }\end{array}$ \\
\hline
\end{tabular}

The Litany phase of the CLA reveals underlying themes and categorizations as they emerged from the data. The Word Cloud depicts these emergent themes. Table 2 shows a breakdown of the constructs identified and the number of times those constructs were used in the 145 statement summaries from the 
respective documents. The number of social systems categories the construct occurred in ("Categories") will be important information for the next layer of CLA. (See Table 2 and Figure 2 below.)

TABLE 2

CONTENT ANALYSIS OF KEY CONSTRUCTS

\begin{tabular}{|l|c|c|}
\hline Construct & Occurrences & Categories \\
\hline connect & 32 & 5 \\
\hline socialcontract & 26 & 5 \\
\hline technology & 21 & 5 \\
\hline data & 20 & 5 \\
\hline lifelonglearning & 17 & 5 \\
\hline transparency/trust/verification & 17 & 5 \\
\hline security & 13 & 5 \\
\hline selfactualization & 11 & 5 \\
\hline equity & 10 & 5 \\
\hline change & 15 & 4 \\
\hline credentialing & 7 & 4 \\
\hline work & 7 & 4 \\
\hline access & 6 & 4 \\
\hline governance & 20 & 3 \\
\hline autonomy & 13 & 3 \\
\hline experience & 7 & 3 \\
\hline costs & 3 & 2 \\
\hline
\end{tabular}

FIGURE 2

WORD CLOUD OF KEY CONSTRUCTS

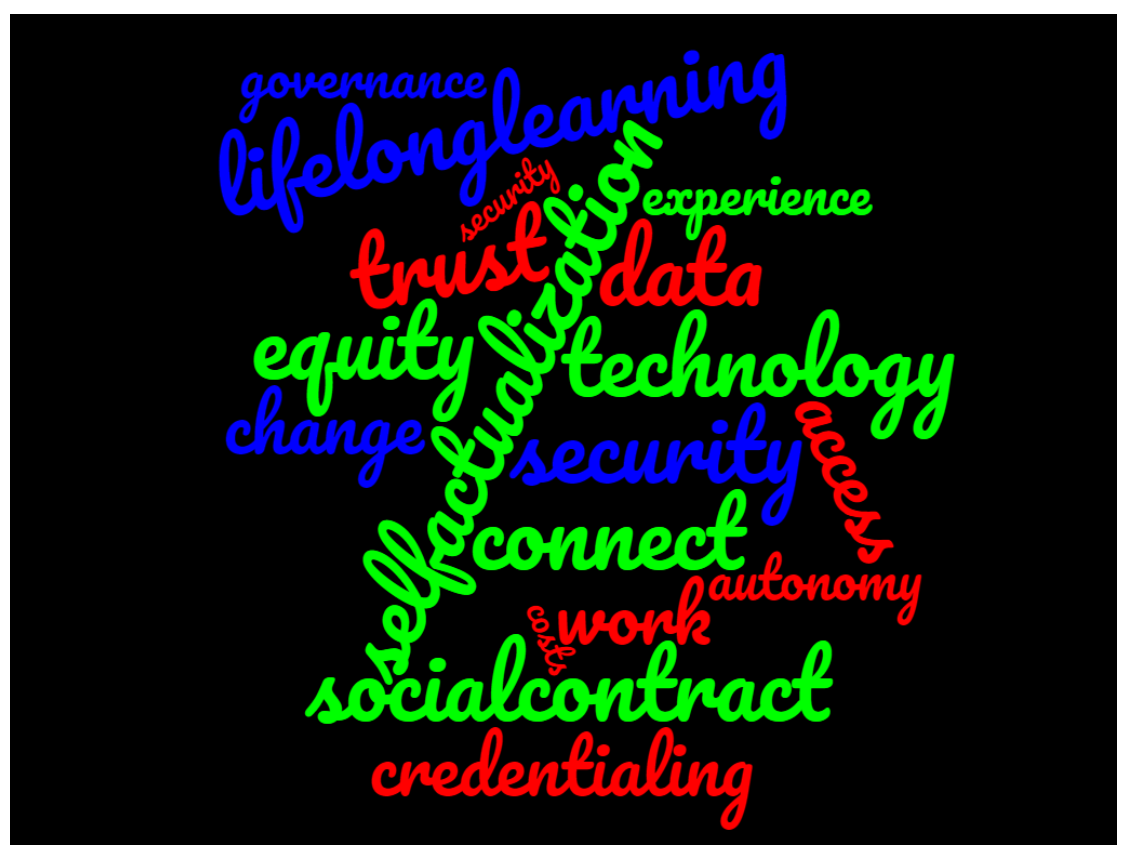

34 Journal of Higher Education Theory and Practice Vol. 22(1) 2022 
As can be seen from the data summary chart (Table 2), reflected in the Word Cloud (Figure 2), selfactualization and lifelong learning were key themes across both documents. Self-actualization statements focused on increasing individuals' capacities for creativity, critical thinking, meaningful work and leisure, and alternative ways of making a living, including the increased emphasis on self-employment. Lifelong learning statements focused on building capacities for learning-to-learn, as-needed learning, and meaningful learning, de-emphasizing rote learning, disconnected knowledge, and formal education. Several of the statements specifically mentioned the role of technology in lifelong learning through augmented and virtual learning as well as artificial intelligence as important extensions to how individuals know and navigate their worlds. Autonomy was often paired with one of these two constructs but was treated as a separate category since it focused on empowerment, control, independence, and opportunity.

Technology, equity, and connections, whether across social agencies, individuals, or in the workplace, were also themes that occurred with regularity. While some of the technology statements focused on new technologies, others noted the role technology could play as a social good for selfactualization, lifelong learning, connecting with employers and others, and providing for more equitable opportunities. Connections was treated as a separate category because of the number of times and ways it was used to describe relationships, collaborations, national and international initiatives, globalization, and emergence of new ideas, creations, and structures.

A new social contract was explicitly discussed in the MP recommendations and inferred in the ACE document. The New Social Contract summarized ideas such as universal basic income, redistribution of wealth, freeing humans from routine work, rethinking the value of work to include activities that do not contribute directly to financial or business advantage, workers' rights to control their own information, individualized construction and representation of work-related accomplishments, skills, and capabilities, and social support for self-actualization and humanistic contributions to society.

Data and security were treated separately in the analysis as some statements described the physical generation, ownership, storage, and mechanisms for accessing data, while others focused on security in terms of data, personal or physical safety, and financial sufficiency. Specific governance concerns were especially addressed in statements about creating standards, establishing new guidelines or governance structures, developing new reporting mechanisms, providing oversight over new technologies, or forming new contractual relationships.

Transparency, trust and verification were terms especially associated with specific technology applications such as blockchain but also included values statements associated with a new social contract and ability of individuals to have mechanisms for instilling trust and verifying processes across social applications. Verifiable credentials were associated with equity statements to provide fairer and more diverse ways for individuals to demonstrate qualifications and expertise.

Change was addressed in terms of rapidity of change, the need for fast-moving learning and credentialing, emergence of new technologies, frequency of job transformations, continuous learning needs, infrastructure of research and development to support and provide mechanisms for important social changes, and pressures on social systems, including education, to need to change.

Credentialing, work and experience were treated as separate categories. Credentialing focused on the need to provide evidence of learning, the dynamism of the learning environment with the proliferation of informal and formal credentialing options, evaluation and trust of credentialing sources, and the need for standards to support individualized and emergent efforts to demonstrate competencies. Work delineated the need for new kinds of labor unions for self-employment, alternative kinds of and value for work contributions, new ways of seeking employment, and support for virtual workers. Experience was described in the documents from perspectives of demonstrating competencies through experience as well as augmented experiences through technology.

A more in-depth analysis of the ideas conveyed in these two documents occurs with the next level of analysis. The results of the systems-level phase of the CLA are described below. 


\section{Systems}

The systems level layer of the CLA explores system connections and relations across the social systems categories. In this study, the five system categories of government and governance (G), business and labor (BL), science and technology (SL), education and learning (EL), and culture and arts (CA) were used. The list generated through the litany analysis of the two reports as depicted in Table 2 above, includes the number of social system categories in which each construct was found. From a social inquiry perspective, constructs that occur across more social system categories reveal a stronger connection to underlying beliefs, values, expectations, and visions about the future. The systems-level analysis will be important to provide insights into the emerging worldview as revealed through the Millennium Project (MP) and American Council on Education (ACE) documents.

The constructs that occurred across all of these social categories were: connect, social contract, technology, data, lifelong learning, transparency/trust/verification, security, self-actualization and equity. Constructs appearing in at least four categories were: change, credentialing, work, and access.

The narrative that is unfolding in the analysis across social systems has a strong emphasis on a new social contract that utilizes technology and supports control of individual data for connecting across educational and work environments. An acknowledgment of the rapidity of change and the changing work ecosystem compels new forms of credentialing and needs for mechanisms to ensure the security and availability of data to demonstrate competencies and provide more fair access to job-related opportunities and experiences. New technologies compel the need to develop systems that are trustworthy and protect individual information while allowing for ready access and sharing of data to support employment and jobrelated opportunities. Collaboration and connections across social systems, agencies, governments, and scientific endeavors is valued and supported through technologies. And learning demands for individuals and needs for society compel a shift in attitudes away from formal education as the predominant form of credentialing to lifelong learning and demonstration of competencies and skills through a variety of mechanisms including badging, experiences, and social media demonstration of impact.

While the focus of both documents gravitated toward the positive aspects of technology and change for the future, there were values and expectations that presented cautionary concerns. With new technologies and the development of advanced information systems, privacy and control of data were of concern. Likewise, especially apparent in the MP document, were concerns about augmented capacities through technology that challenge what it means to be human. Issues of when augmentation technologies and artificial intelligence cross the line to create non-human cyborgs and the relationship between human workers and non-human robots endowed with artificial intelligence and decision-making capabilities were raised as areas of concern that have implications for changing workforce expectations and demands. While neither document advocated for increased governmental control or oversight and both supported more interagency, intergovernmental, global cooperation, concerns were raised about the needs for transparency, security, and ability to verify information and support human workers in their individual pursuits for meaningful employment and self-actualization.

Whether explicitly addressed or inferred, blockchain technologies were seen as a promising technology to address data sharing and the relationship between education and work. Although costs were raised as an issue only in terms of the costs of replacement of old systems with new technologies and the costs of moving to scale with new technologies such as blockchain data systems, there was an implication that ultimately these technological advances could transform society in positive ways and these initial challenges could be overcome.

Especially apparent in the MP document, shifting economies due to more self-employment, guaranteed minimum income, and an economy that also places value on individual contributions to society raised issues of a very different work-life environment that supports self-actualization, creativity, and work-life balance. The issue of equity was also apparent and emphasized equal opportunity, equal access, equal recognition of possible contributions and an opening of many routes to demonstrate competencies and skills for employment opportunities beyond academic credentialing.

The vision of the future of education as related to blockchain technologies emerging through the social systems analysis begins to convey a new world view. This will be explored in the next section of the paper. 


\section{Challenging Worldviews}

A worldview is a story or narrative about how things are in our social realities. Social systems inquiry supports the identification and articulation of the underlying world view of a society as important to understanding and changing social contexts.

As described by Inayatullah (1999),

Discerning deeper assumptions behind the issue is crucial here as are efforts to revision the problem. At this stage, one can explore how different discourses (the economic, the religious, the cultural, for example) do more than cause or mediate the issue but constitute it, how the discourse we use to understand is complicit in our framing of the issue. Based on the varied discourses, discrete alternative scenarios can be derived here. (p. 820)

The worldview emerging from the litany and systems examinations of the documents reveals specific challenges to existing myths. Exploring these emerging myths and the existing myths that are being challenged are important steps for developing new metaphors and transformational views of preferred futures in the fourth level of the CLA analysis.

The myths being challenged through the CLA analysis are:

- The Myth of Knowledge

- The Myth of Centralized Control

- The Myth of Average

- The Myth of Work

- The Myth of Change

Each of these myths will be explored from the perspective of what the traditional myth is and how it is being extended, challenged, or replaced in these documents. This discussion will convey an emerging worldview with emerging understandings and new myths and metaphors.

\section{The Myth of Knowledge}

The Myth of Knowledge being challenged in both documents is the idea that knowing, and knowledge are associated with and confirmed by academic accomplishment. The dimensions of this myth include not only problematizing how and where learning occurs and how it is credentialled but supports multiple ways of knowing and doing that are valued and needed for a new kind of workforce in a technologically dynamic and rapidly changing environment. And finally, the challenges to traditional knowledge approaches displaces the idea that learning comes before doing, that advanced learning of skills and competencies is sufficient in emerging employment contexts, and that learning ends after formal schooling.

As the myth of knowledge is being challenged, there are new values and expectations being communicated. These values and expectations include valuing and supporting lifelong learning, valuing different kinds of knowing and doing, valuing ability to change, retool, and learn new skills, and valuing a wider range of knowledge, skills, dispositions, and competencies than are traditionally the outcomes of formal education.

Blockchain data systems have the potential to offer individuals, businesses and other employers or consumers ways of accessing and determining the qualifications of an individual seeking employment or contracts. Blockchain technology opens up possibilities for individuals to demonstrate their competencies and skills through a variety of experiences, trainings, credentials, and even social media recommendations and supports their lifelong learning endeavors. Blockchain technologies offer individuals the opportunity to compile specific and relevant life-experiences for specific employment opportunities and to creatively think about their unique qualifications, passions, and desires for meaningful work experiences.

\section{The Myth of Centralized Control}

Both documents also convey the challenges associated with rapid technological and social change and the inability to manage, control, or even predict future needs and possibilities. The idea that social 
institutions as well as individuals can prepare for the future or that organizations and accrediting agencies can specify the knowledge, skills and dispositions needed for the future is replaced by a recognition that because things are changing so rapidly, we cannot prepare for the future by trying to control or anticipate change. Organizationally, this myth of hierarchies and management structures that are run by a few decision makers at the top and expectations for efficiency and information flow that is uniform and consistent are problematized by challenges to one-size-fits all assumptions, expectations for standardization and consistency across contexts, and communication styles that are designed to reach and/or impact all audiences.

The values emerging from a challenge to centralized control include a recognition of the power of connection and networks rather than hierarchies and structures, the value for adaptive learning and response to changing contexts and demands, and the value for being able to work collaboratively with fluid and dynamic workgroups. Long-term strategic planning and goals are replaced by adaptive and visioning plans, and flexible/dynamic goals that can be adjusted and pivoted as contexts change.

Blockchain technologies support decentralized control of data systems and storage of information to make accessibility and usability more accommodating and tailored to specific contexts and needs. So, for example, individuals applying for different jobs can make available relevant information about past experiences rather than going to different universities for copies of transcripts, credentialing agencies for proof of badging or other certification accomplishments, professional development sponsors, or other individuals or agencies that can provide evidence of accomplishment, proficiency, or work skills competencies.

\section{The Myth of Average}

The myth of average has long been recognized, yet we continue to base much of our educational systems on it. As Todd Rose described in his book The End of Average (Rose, 2016), the US Military came to the conclusion that the average was a myth in the 1950's as they were trying to design the perfect fighter jet cockpit. They calculated the average of hundreds of pilots across six measures to design the perfect cockpit. Once it was designed, they found fewer than $4 \%$ of pilots actually matched on even as few as three different measures. They determined the need for adaptive designs that could accommodate differences among pilots.

The myth of average controls how we measure student success, evaluate teaching and learning, determine awards and recognize accomplishments, and define what is "normal." The normal curve, as a mathematically defined measure of "average" is used to interpret test results for graduation, college admissions, and other competitive accesses. Students and teachers are categorized as above or below average, and institutions such as schools and school systems are deemed as "failing" based on measures that compare them against standard measures using some form of averaging and normalizing.

Companions to the myth of average are the ideas that things can be measured, and one-size-fits-all. For example, the Intelligence Quotient (IQ) test was developed in 1917 to identify army soldiers in WWI who had superior spatial and logical reasoning skills deemed necessary for leadership and logistical warfare at the time. For the remainder of the $20^{\text {th }}$ century, IQ became an important measure of intelligence used to identify students for gifted and talented programs and participation in distinguished societies such as MENSA. Even when Gardner (1983) developed his multiple intelligences research to show different facets of intelligence, mathematics and logical thinking continued to be deemed as indicators of intelligence and the subjects that teach them, including mathematics and writing, were given special status in the hierarchy of curriculum privilege.

Although inherent and systematic biases of standardized testing have long been explored (see, for example, Meaghan \& Casas, 2004), education, as a whole, continues to invest in and maintain comprehensive assessment and accountability infrastructure to evaluate just about anything in education they feel can be measured including student achievement, curriculum and teaching effectiveness, teachers, schools and school districts, colleges and universities, and certifications. Blockchain technologies open up this system of one-size-fits-all to accommodate multiple and diverse measures, metrics and information to demonstrate competencies and preparation. With blockchain technologies, in addition to maintaining 
control of their individual scores, degrees and certifications, individuals can expand how they choose to represent themselves and their unique skills.

\section{The Myth of Work}

The myth of work conveys the relationship between workers, social contribution, and individual identity. The myth of work is supported by hierarchical structures that convey value for those higher up in the hierarchy. And higher status in the hierarchy typically is rewarded by higher pay. Managers are considered to have more expertise and receive more money because they are perceived to have specialized skills that allow them to supervise those below them on the hierarchy, making them more valuable. CEOs and corporate leaders are the highest paid and are at the apex of the workforce hierarchy. Manual labor is perceived as less specialized and of lower status which is also reflected in pay. Salary scales reflect this hierarchy, historically compelling individuals to get into the workforce at a young age and work themselves up the ladder of success.

One's position in the workforce hierarchy also impacts identity. Being a manager of people rather than a laborer not only results in higher income but higher social status. When children are asked what they want to be when they grow up, they are being steered to jobs with status and identity rather than being asked what they like to do or how the want to make a difference in the world.

Education is intimately tied to the myth of work. Traditionally, the more educational accomplishment one has, the higher up in the hierarchy one is able to begin their profession and advance through their chosen field. Higher pay and higher education are also reflective of expectations for greater contributions. Persisting from our industrial roots, pay and value are associated with profits and innovations.

Until recently, the expectation was that one would select their job or field matching their particular skills and work themselves up through the career ladder, staying in one field and often in one organization for their entire career, retiring at age 65 . This myth of work has been disrupted not only by individual mobility and industry instabilities, but by the rapid emergence of new industries, technologies and forms of employment.

Especially apparent in the Millennium Project study, the rise in alternative economies and selfemployment have challenged traditional employment trends and values. Individuals do not want to stay in "dead-end" jobs or work as a cog in a system from which they derive no meaning and only contribute to the business profitability. Not only are the workplace and kinds of jobs changing, but worker expectations challenge the desirability of work and disrupt the payment hierarchy. Values are shifting as "essential workers" are perceived not as those who contribute to business profit but who contribute to a social good.

Blockchain technologies can facilitate not only the increased mobility (geo-spacially as well as from job to job) of workers but the ability of workers to demonstrate and pursue their passions and unique interests that may not be captured through traditional academic or workforce achievements. As jobs, industries, and the economy become more fluid, the ability to quickly and accurately represent passions, skills, interests, and contributions will become more important for utilizing and supporting talent and emerging ways of supporting the social good.

\section{The Myth of Change}

Although it almost seems superfluous to describe the myth of change as a pivotal challenge to the existing worldview, there has been sufficient evidence that, although people recognize the speed of change and the challenges of emerging technologies, they do not operate as if the world is really changing. Even though, by some measures, "knowledge" is no longer doubling every 12 months but getting closer to doubling every 12 hours (Schilling, 2013), many people continue to perceive change as incremental or cyclical. They persist in trying to maintain or recreate the past and consider changes to traditional values or structures as aberrant, unnecessary, or temporary. They deny the impacts humans have had on our environment and feel all change is both incremental, manageable and reversable.

The myth of change is perhaps the most pervasive challenge to implementation of blockchain technologies in education because traditional beliefs about employment, the nature of meaningful and valuable work, and expectations for individual accomplishments persist. The disruption of existing social 
structures such as testing, accountability, data management, and assessment in schools, alone, represents a tremendous reinvestment of money and loss of control. We are so wedded to the value of a high school or college diploma, that opening up systems to demonstrate competencies, skills and dispositions that may disrupt traditional education will be met with challenges not only from those within the education system, but industries that have grown out of supporting educational testing, assessment, accountability and accreditation.

The new social contract as an expanded understanding of what individuals should expect from their society confronts the myth of change and exposes challenges to meaningful work, individual worth, fairness, income gaps, universal healthcare, and minimum basic income. Transparency, trust, and verification as well as strong desires for security and a drive for self-actualization are results of the social inquiry analysis that convey we are undergoing significant social transformation.

The challenges to traditional worldviews are helpful for constructing new myths and metaphors for the future, impacting work and education. Blockchain technologies will have a role to play in these new transformational visions.

\section{New Myths \& Metaphors}

As described by Dator (2011), there are four basic perspectives of the future as we consider social change initiatives. The focus of this inquiry is transformational change that explores the possibilities of blockchain technologies in education in a fundamentally different social environment from the present. The social systems analysis ensures the plausibility of this futures perspective.

The Causal Layered Analysis (CLA) approach (Inayatullah, 2006) is especially valuable for exploring transformative futures with an increasing deepening of inquiry down to core values, beliefs and understandings as conveyed by underlying social metaphors and myths. The level 3 analysis explored challenges to existing worldviews by exposing the myths of knowledge, centralized control, average, work and change. This fourth level of analysis will consider possible myths to accommodate an emerging worldview implicit in these challenges to the modern or traditional worldview.

Inayatullah (1998) describes this fourth layer of analysis as "more concerned with evoking visual images, with touching the heart instead of reading the head" (p. 820). Figure 3, below, provides an image to organize a discussion of the futures of blockchain approaches in education based on the social inquiry analysis.

The image below is a picture of a nautilus. The name Nautilus has its roots in the Latin word for "sailor" not only because of nautiluses' unique design of buoyant structures but because of their ability to propel themselves through the ocean. As a nautilus ages, it adds chambers to its skeletal structure. Older chambers become "static" and hard, while newer chambers are more pliable and supple. Nautiluses have tentacles, like octopuses, that are used to interact with their environment.

I am using this image of a nautilus as a visual metaphor of the future of education and centrality of blockchain technologies. At the core of the nautilus metaphor is the "hard wired" past with traditional perceptions of knowledge, control, average, world of work and change. These are semi-permanently hardwired myths of the modern era as the social inquiry analysis has shown to be problematized by changes in technology, work, and expectations for the future through the analysis of the Millennium Project (MP) and American Council on Education (ACE) projections. Emerging technologies such as blockchain technologies as well as virtual reality, robotics, and artificial intelligence have created a new ocean of steering demands requiring new understandings, sensibilities, and expectations for identity, change and navigation strategies of our complex social environment.

The nautilus is also an interesting metaphor because of how it grows and transforms in recursive, dynamic patterns. A nautilus constructs the future but never leaves the past behind. 


\section{FIGURE 3 \\ VISUAL IMAGE OF EMERGING TRANSFORMATIONAL METAPHOR}

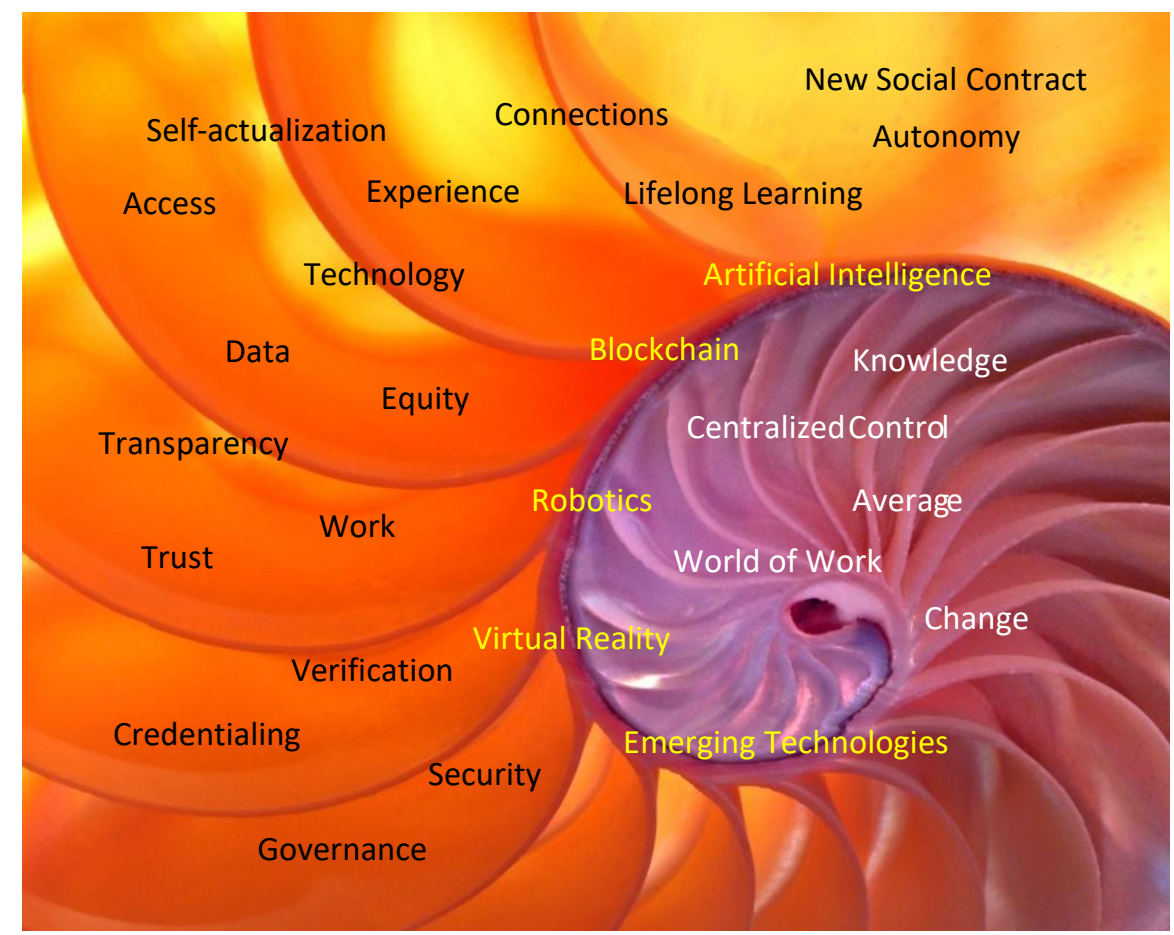

The words in black in Figure 3 reflect the constructs that emerged through the social systems inquiry. As the future of education is explored, filtered through these core ideas, we see emerging a very different perspective of education and need for appropriate use of emerging technologies, include blockchain technologies. The navigable waters of society provide nourishment or support for these ideas, as shown in the social systems analysis.

Blockchain technologies will allow for more flexible ways of demonstrating competencies, interests, capacities, skills, and desires, supporting self-actualization and individual autonomy to construct and communicate our individual identities. The nautilus metaphor compels us to be lifelong learners as learning is no longer perceived as terminal preparation for existing jobs through formal education but as on-going and continuous development throughout the lifespan. A new social contract suggests shifting values for work that contributes to society in ways beyond just financial advantage and supports more fair and equitable distribution of wealth and services including universal healthcare, education, and guaranteed minimum income. Access to data and the sharing of specific subsets of personal data are secure and transparent to support immediate availability and mining for different purposes. New governance systems as well as credentialing and verification systems are needed to protect core values for equity, transparency, accessibility, and authentication.

What is important about this metaphor is not so much the narrative of the nautilus-blockchain education futures, but an understanding of the dynamic between the hard-shelled myths in need of change and the emergence of educational futures that address the challenges and visions as described in the MP and ACE documents. It is interesting that one of the nautilus' protective abilities is to "go deep" in the ocean to avoid prey. While the growth of the nautilus is recursive, its motion includes vertical as well as horizontal propelling action. Going deep, as we have done through the CLA approach, is metaphorically and practically important for our survival through transformational change. The final discussion of the guiding questions will address this latter point. 


\section{DISCUSSION}

The results of this study, as summarized below by answering the guiding questions of this inquiry, are not merely speculative but grounded in this social systems inquiry. The value of the social systems approach using the CLA futuring strategy has been to provide a deeper perspective of the challenges and obstacles to change as well as a breadth of analysis through the social systems inquiry.

\section{Question 1}

The first research question was: What are the opportunities and challenges to public education introduced by blockchain technologies? While many different studies and publications have addressed the first part of this question, the second part is especially relevant to our analyses.

The opportunities, as the ACE report, among others has already disclosed, include supporting lifelong learning and providing more flexible and adaptive means for sharing relevant information about qualifications and skills for work opportunities. Blockchain technologies have the features of being secure, adaptable and not requiring centralized control or authority. They are transparent and trustworthy from the perspective of data not being changeable or lost.

The challenges blockchain technologies present for education, especially pubic education, are especially apparent as underlying myths are explored. The myths of knowledge, centralized control, average, work and change are obstacles to the implementation of blockchain technologies and the personal and financial investments that will be required to implement blockchain approaches.

As Smyre and Richardson (2016) suggest with many transitory changes, there are often needs for parallel approaches to change, where new approaches coexist with older technologies and understandings. This parallel approach to blockchain uses in education is already emerging. Ultimately, however, a paradigm shift about the purpose and role of education will need to occur because of the implications for public financing and oversight of educational institutions and outcomes. The assessment and accountability industries will shift from supporting and being supported by K-12 education to providing new ways to document significant life experiences and capacities relevant to employment and lifelong learning.

The social inquiry analysis points to the transformational needs of a society for fundamental change to occur. The challenges blockchain applications to education introduce go well beyond the development of the technology or the implementation of blockchain strategies. While existing research suggests the plausibility of and even possibilities for the implementation of blockchain technologies in education, the desirability and ultimate adoption of blockchain technologies in education will require going deeper to address the underlying myths that are obstacles to transformational change.

\section{Question 2}

The second research question asks: How may blockchain technologies support a different vision of the future of education? A response to this question will extend from the nautilus metaphor to describe a different kind of educational ecosystem.

While the first research question exposes the obstacles and challenges to adopting blockchain technologies in education, the second question turns the question around and asks how blockchain technologies can support a vision of the future of education. At its deepest levels, blockchain education itself becomes a root metaphor for education.

Like the recursive growth of the nautilus, blockchain data grow and evolve, always maintaining a history but evolving as new information and exchanges occur. Figure 4 provides a sample blockchain schemata using what is known as a Merkle Tree to provide a deeper understanding of how we might consider lifelong learning. The Merkle Tree is used to encode data and provide a comprehensive history of all transactions within the blockchain. 


\section{FIGURE 4 \\ MERKLE TREE FOR LIFELONG LEARNING BLOCKCHAIN}

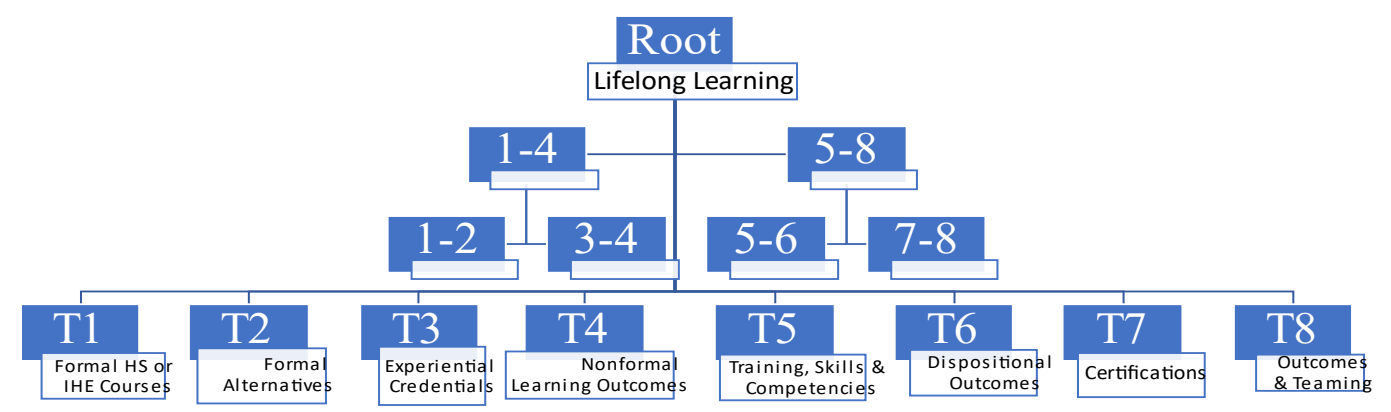

\section{CONCLUSION}

Social inquiry approaches using futuring strategies support discussions of possible, plausible, and desirable futures. Unlike traditional forms of research, the ultimate goal of this research is not to interpret the past or predict the future, but to inspire discussion and possibilities for the kinds of futures we need and want. Because futures social inquiry is not "RE-search" in a technical sense, it may be dismissed as real research. But the method of social inquiry to explore the potential futures of an issue across social systems categories fits well within the discourse of complex social systems theory, postmodernism, and futures literacy. As a researcher using futures strategies with social inquiry, the goal is to inspire and inform future beliefs and action.

The story of the new educational myth will incorporate a story of lifelong learning and inquiry supported by technology and new ways of knowing that include futuring skills driven by entrepreneurial mindsets for self-employment options and multiple ways of contributing to society in ways that are selfactualizing and consistent with values of equity, justice, and community. Traditional binaries of power and relationship are disrupted in this new education story to understand multiple intelligences and ways of interacting that provide opportunities for everyone to participate fully in making a difference in the world.

What are the stories we want to tell ourselves about the future, and the future of education? Do we want to tell a story of promise, hope, and change, where we co-exist with technology and each other in fair, compassionate, learning environments? Or do we want to tell the story of dysfunction, decline, decay, and end-times? Futures inquiry using social systems and CLA approaches provides a hopeful plausible and desirable future perspective of education. Beyond adaptive response to possible futures, this approach provides a grounding for creating visions of the future of education and blockchain applications that are driven by important social parameters that are actionable and within the realms of the possible and desirable.

\section{REFERENCES}

Alarcon, J.L., \& Ng, C. (2018). Blockchain and the future of accounting. Pennsylvania CPA Journal, 88(4), 26-29. Retrieved from https://proxying.lib.ncsu.edu/index.php/login?url= https://www-proquest-com.prox.lib.ncsu.edu/trade-journals/blockchain-futureaccounting/docview/2002003571/se-2?accountid=12725

Braun, V., Clarke, V., Hayfield, N., \& Terry, G. (2019). Thematic analysis. In P. Liamputtong, Handbook of Research Methods in Health Social Sciences (pp. 843-860). Singapore: Springer. DOI: 10.1007/978-981-10-5251-4_103

Chen, G., Xu, B., Lu, M., \& Chen, N-S. (2018). Exploring blockchain technology and its potential applications for education. Smart Learning Environments, 5(1), 1-10. DOI: 10.1186/s40561-0170050-X 
Dator, J. (2011). Futures studies. In W.S. Bainbridge (Ed.), Leadership in Science and Technology (pp. 32-40). Thousand Oaks, California: Sage Reference Series.

Duriau, V.J., Reger, R.K., \& Pfarrer, M.D. (2007, January). A content analysis of the content analysis literature in organization studies: Research themes, data sources, and methodological refinements. Organizational Research Methods, 10(1), 5-35.

Evans, T.J. (2019). Cryptokitties, cryptography, and copyright. American Intellectual Property Law Association Quarterly Journal, 47(2).

Gardner, H. (1983). The theory of multiple intelligences. Heinemann.

Glenn, J. (2020). Work/Technology 2050: Scenarios and actions. Millennium Project. Retrieved from http://www.millennium-project.org/projects/workshops-on-future-of-worktechnology-2050scenarios/

Greene, J.C. (2006). Toward a methodology of mixed methods social inquiry. Research in the Schools, 13(1), 93-99.

Greene, J.C. (2008, January). Is mixed methods social inquiry a distinctive methodology? Journal of Mixed Methods Research, 2(1), 7-22. Retrieved from http://citeseerx.ist.psu.edu/viewdoc/download?doi=10.1.1.579.3700\&rep=rep1\&type=pdf

Gürkaynak, G., Y1lmaz, I., Yeşilaltay, B., \& Bengi, B. (2018). Intellectual property law and practice in the blockchain realm. Computer Law \& Security Review, 34(4), 847-862.

Haber, S., \& Stornetta, W.S. (1991a). How to timestamp a digital document. In A. Menezes \& S.A. Vanstone (Eds.), Proceedings of the 10th annual International Cryptography Conference on Advances in Cryptography (pp. 437-455). Berlin: Springer-Verlag.

Haber, S., \& Stornetta, W.S. (1991b). How to timestamp a digital document. Journal of Cryptology, 3(2), $99-111$.

Höhne, S., \& Tiberius, V. (2020). Powered by blockchain: Forecasting blockchain use in the electricity market. International Journal of Energy Sector Management, 14(6), 1221-1238. http://dx.doi.org.prox.lib.ncsu.edu/10.1108/IJESM-10-2019-0002

Hoy, M.B. (2017). An introduction to the Blockchain and its implications for libraries and medicine. Medical Reference Services Quarterly, 36(3), 273-279. https://doi.org/10.1080/02763869.2017.1332261

Inayatullah, S. (1998). Causal layered analysis: Poststructuralism as method. Futures, 30(8), 815-829.

Inayatullah, S. (2008). Six pillars: Futures thinking for transforming. Foresight, 10(1), 4-21. https://doi.org/10.1108/14636680810855991

Krzyzanowski-Guerra, K., \& Boys, K.A. (2021). A new food chain: Adoption and policy implications to blockchain use in agri-food industries. Applied Economic Perspectives and Policy, pp. 1-26. https://doi-org.prox.lib.ncsu.edu/10.1002/aepp.13163

Lemoie, K., \& Soares, L. (2020). Connected impact: Unlocking education and workforce opportunity through blockchain. American Council on Education. Retrieved from https://www.acenet.edu/Documents/ACE-Education-Blockchain-Initiative-Connected-ImpactJune2020.pdf

Li, J. (2020). Research on the development and application of 'Blockchain+" education. Journal of Physics: Conference Series (1607). The 2020 International Symposium on Electronic Information Technology and Communications Engineering, 19-21 June, 2020, Jinan, China. DOI: 10.1088/1742-6596/1607/1/012089

McKinney, S.A., Landy, R., \& Wilka, R. (2018). Smart contracts, blockchain, and the next frontier of transactional law. Washington Journal of Law, Technology \& Arts, 13(3), 313-347.

Millennium Project. (n.d.). Retrieved from http://www.millennium-project.org/

Miller, R. (Ed.). (2018). Transforming the future: Anticipation in the $21^{\text {st }}$ century. New York: Routledge.

Nakamoto, S. (2009). Bitcoin: A peer-to-peer electronic cash system. Retrieved from https://bitcoin.org/bitcoin.pdf

Neuendorf, K.A., \& Kumar, A. (2016). Content analysis. In EDITORS, The International Encyclopedia of Political Communication. John Wiley \& Sons, Inc. https://doi.org/10.1002/9781118541555.wbiepc065 
Rose, T. (2016). The end of average: How to succeed in a world that values sameness. Penguin UK.

Schaffhause, D. (2020). Report: Blockchain 'Holds Promise' for Ed. Campus Technology. Retrieved from https://campustechnology.com/articles/2020/06/18/report-blockchain-holds-promise-for-ed.aspx

Schilling, D.R. (2013). Knowledge doubling every 12 months, soon to be every 12 hours. Industry Tap. Retrieved from https://www.industrytap.com/knowledge-doubling-every-12-months-soon-to-beevery-12-hours/3950

Sharples, M., \& Domingue, J. (2016). The blockchain and kudos: A distributed system for educational record, reputation and reward. In K. Verbert \& M. Sharples (Eds.), Adaptive and adaptable learning (pp. 490-496). Springer, Cham. https://doi.org/10.1007/978-3-319-45153-4_48

Skiba, D.J. (207). The potential of Blockchain in education and health care. Nursing Education Perspectives, 38(4), 220-221. https://doi.org/10.1097/01.NEP.0000000000000190

Srivastava, G., Dhar, S., Dwivedi, A.D., \& Crichigno, J. (2019). Blockchain education. 2019 IEEE Canadian Conference of Electrical and Computer Engineering. Retrieved from https://ieeexplore-ieee-org.prox.lib.ncsu.edu/stamp/stamp.jsp?tp=\&arnumber=8861828

Swan, M. (2015). Blockchain: Blueprint for a new economy (1st ed.). Sebastopol, CA: O'Reilly Media.

Teichert, C., \& Matsumoto, T. (2010). The Ancestry of the Genus Nautilus. In W.B. Saunders \& N.H. Landman (Eds.), Nautilus: The Biology and Paleobiology of a Living Fossil (pp. 25-32). Springer. doi: 10.1007/978-90-481-3299-7_2

Wallace, B. (2011, November 23). The rise and fall of Bitcoin. Wired. Retrieved from https://www.wired.com/2011/11/mf-bitcoin/

Whitaker, A. (2019, Summer). Art and blockchain: A primer, history, and taxonomy of blockchain use cases in the arts. Artivate: A Journal of Entrepreneurship in the Arts, 8(2), 21-46. https://doi.org/10.34053/artivate.8.2.2

Zhou, L., Lu, R., \& Wang, J. (2020) Development status, trends and challenges in the field of "blockchain and education. Journal of Physics: Conference Series 1621 012112. doi:10.1088/1742-

$6596 / 1621 / 1 / 012112$ 